\title{
Optimisation of the Lift Carrying Frame Construction by Using Finite Element Method
}

\author{
Paweł Lonkwic \\ 1 The State School of Higher Education in Chełm, ul. Pocztowa 54, 22-100 Chełm, Poland \\ e-mail: plonkwic@gmail.com
}

\begin{abstract}
Numerical analysis of the carrying frame subassemblies strength installed in the friction lift was presented in this article. Two models of the frame loading were introduced. One of them was applied during loading and the other one during regular operation with nominal load capacity. Finite Element Method was used for calculations. It allows mapping the actual operating conditions by using commercial SolidWorks software. Modifications in the frame key subassemblies from geometrical point of view were proposed. Due to them, the frame weight was reduced by $20 \%$ and a safety coefficient was maintained at the level of 3 .
\end{abstract}

Keywords: FEM, a friction lift, simulation, modelling, Solid Works

\section{INTRODUCTION}

Numerical methods in optimising the construction become more and more popular. They are used both to save time and money instead of expensive construction prototyping. The publications referring to the subject of modelling in different fields of science and technology can be found in literature. The results of experimental tests and numerical simulations for braking process of new CHP 2000 type progressive gear roller were presented in the publication [4]. A commercial packet is used as a numerical tool for calculations using Finite Element Method - ABAQUS program. The results of Finite Element Method simulation for C-shaped frame device to install the joints of sheet metal constructions were presented by the authors of publication [5]. In the analysis of the frame material effort a couple of versions of its geometry including the mass reduction were taken into account. For this purpose, the ABAQUS program was used by the authors. The program allows performing quantitative and qualitative assessment of the frame material effort. In publication [2] the results of numerical analysis for the semitrailer frame construction of variable length and increased load capacity intended to transport over standard loads were presented by the authors. The research aimed at developing reliable FEM numerical models to identify the construction effort and deformation degree under the operating loadings conditions. In the publication [7] authors presented A quadrilateral element with smoothed curvatures for Mindlin-Reissner plates with the use of FEM method. The curvature at each point is obtained by a non-local approximation via a smoothing function. The bending stiffness matrix is calculated by a boundary integral along the boundaries of the smoothing elements (smoothing cells). Numerical results showed that the proposed element is robust, computationally inexpensive and simultaneously very accurate as well as free of locking, even for very thin plates. The most promising feature of our elements is their insensitivity to mesh distortion. In addition to the above-mentioned areas of interest, the FEM method is used in the areas related to magnetism described in publication [6], vibration calculations of various thin-walled structures [8] as well as modelling of liquids, air and thermal loads as well as beams and trusses simulations [10]. 
The analysis results of numerical optimisation of the carrying frame construction in the electrical lift were presented in this research study. Lifting devices (lifts) belong to handling equipment. Once European Union regulations become more restricted, the number of the existing devices being replaced has increased especially in the buildings from 70-ties which are commonly called skyscrapers. Therefore, it is needed to optimise the structural elements from geometrical point of view and influence manufacturing and operating costs significantly.

The carrying frame of the friction lift which was also a carrying subassembly of the cabin (3) was analysed and presented in Fig. 1.

The carrying frame has several key subassemblies: the assembly of the lower beams, the assembly of the upper beams, the vertical beams that join the lower assembly with the upper one and the semi-platforms [11]. Both the assembly of the lower and the upper beams is made

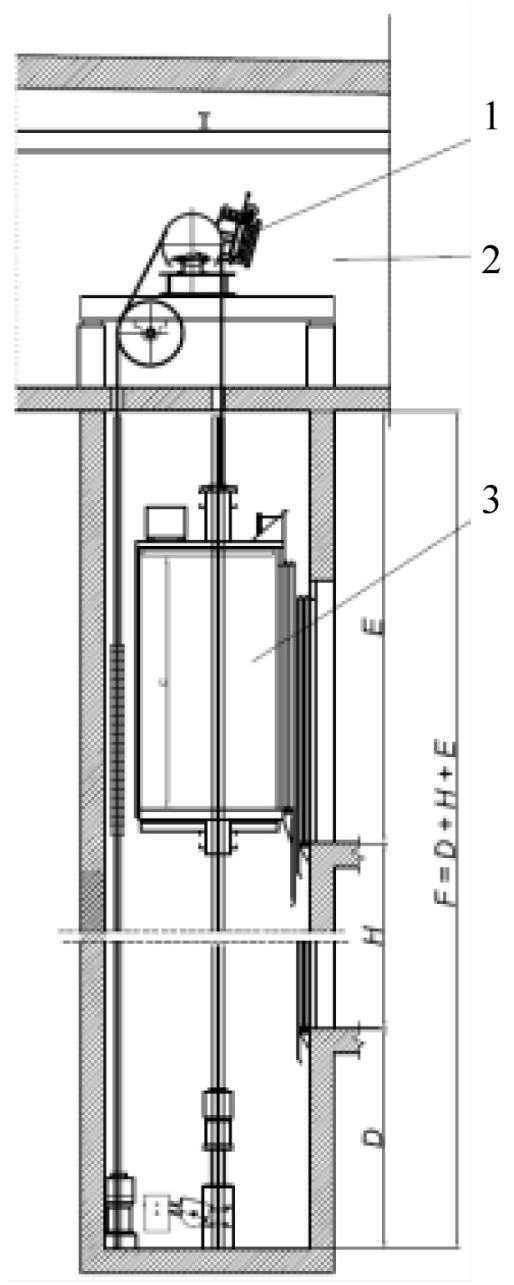

Fig. 1. The cross section through the modernised lift shaft and the engine room [11]. from cold rolled profile (bent with roll forming technology) with a half closed channel bar with the dimensions of $140 \times 50 \times 60 \times 4$, the scheme of which is presented in Fig. 2a and the profile of a semi-platform which is shown in Fig. $2 b$.

Both the upper and the lower assembly are joined together with the vertical channel bars of the frame (1) to which the guide shoes (2) are installed. The guide shoes move along the lift guides. In the upper assembly of the beams and in its central part there is a bracket (4), to which carrying lines are attached. The lift cabin rests on the beams of so called semi-platform (3) which is installed to the lower assembly of the beams - see Fig. 3 .

The lift carrying frame consists of the elements manufactured by bending and weaving technology. In this condition the frame is $132 \mathrm{~kg}$. Optimisation of the frame construction for its mass with a safety coefficient of the construction maintained has a direct impact on two aspects:

- costs connected with the purchase of a device, - rating power of the lift engine including the costs of operation.

The lift carrying frame is intended for the modernisation sector so the load capacity is 550 $\mathrm{kg}$. It is connected with the number of persons that can travel in the cabin at the same time. The lift cabin mass varies from 375 to $405 \mathrm{~kg}$, depending on the equipment. Therefore, the lift carrying frame in regular operation is loaded with $9550 \mathrm{~N}$. The scheme of the lift frame loading can be divided into two stages. The applicable stages are present during the whole period of operation in an alternating way.

The scheme of the frame loading when passengers get into the cabin - see Fig. 4a is recognised as the first scheme of loading. In this case, the force that loads the cabin step is assumed as the loading resulting from charging. The force value is calculated with the formula (1) [9]:

$$
F_{s}=0,4 \cdot g \cdot Q
$$

where: $g-$ acceleration of gravity, $9.81[\mathrm{~m} / \mathrm{s} 2]$;

$Q$ - the lift rated load $[\mathrm{kg}]$

Total loading of the carrying frame construction is assumed as a sum of loading calculated with the formula (1) and the loading resulting from the weight of an empty cabin [9] which is $2160 \mathrm{~N}$.

The second scheme of loading is the effect of the lift operation. The frame is loaded with the maximum loading connected with its surface 
a)

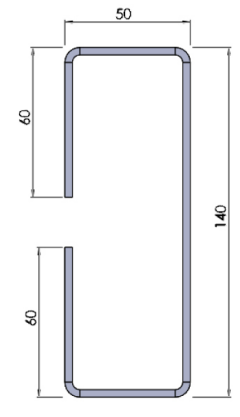

b)

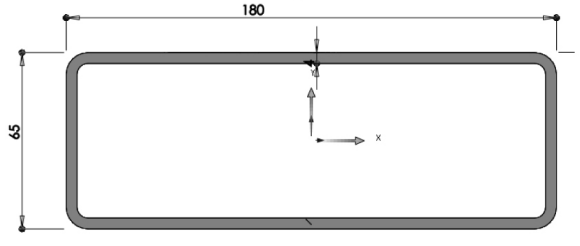

Fig. 2. Crosswise dimensions of the frame carrying beam a) and the semi-platform b).

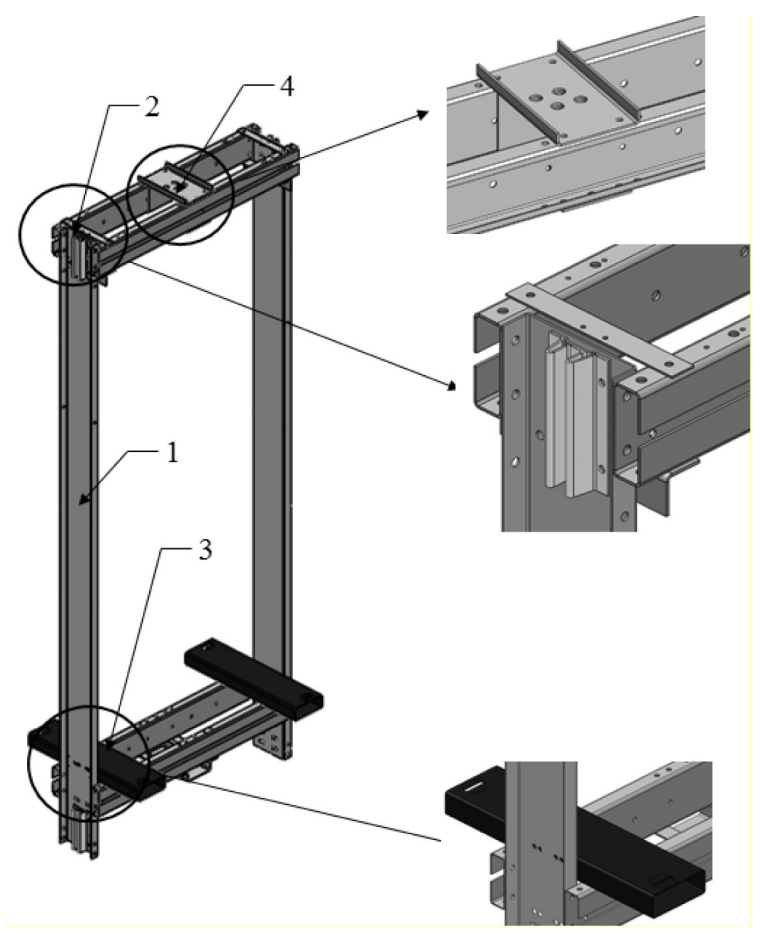

Fig. 3. Model of the friction lift frame.

area, Fig. 4b. In this case, the loading of the lift frame is the sum of masses resulting from a rated load and the mass of an empty cabin. The applicable loading is $9550 \mathrm{~N}$.

With respect to the above, each presented scheme of the frame loading required a separate analysis, individual conditions of mounting and the application of forces that load the frame construction.

\section{The purpose and the scope of numerical analysis}

The numerical analysis was performed to optimise the frame construction with respect to its mass and with the resistance of its component elements maintained. Geometrical model of the analysed object before optimisation (Fig. 5) was prepared in a form of the composition by using Solid Works CAD 2016 software, based on the drawing documentation.

The geometrical model of the carrying frame was the basis to develop a discrete model of the analysed object. This model was used to perform numerical calculations by using Finite Element Method. Geometrical model digitization was conducted by using volumetric finite elements of a global dimension of the mesh element 5 and with tolerance of 0.25 .

For the purpose of optimising the carrying frame construction, the attention was paid to three component elements of the frame: transversal profiles located in the upper and the lower part of the frame and the semi-platform profiles. A new shape of the frame transversal beam (Fig. 6a) with the thickness reduced by $3 \mathrm{~mm}$ and the semi-platform cross section profile (Fig. 6b) were proposed.

The optimised cross sections of structural elements of the carrying frame improved the frame unladen weight which was $105.4 \mathrm{~kg}$. Thus, it was reduced by $26.6 \mathrm{~kg}$, which constitutes $80 \%$ of the frame unladen weight before modifications introduced.

Linear and elastic characteristic for the material was used in numerical calculations due to the fact that there are no permanent deformations of the carrying frame component elements when the frame is operated. All component elements of the frame were made of steel with the following mechanical properties :

- Young model $E=210 \mathrm{GPa}$,

- Poisson ratio $v=0.3$,

- Material density $\rho=7860 \mathrm{~kg} / \mathrm{m}^{3}$,

- yield point $\mathrm{R}_{\mathrm{e}}=230 \mathrm{MPa}$ 

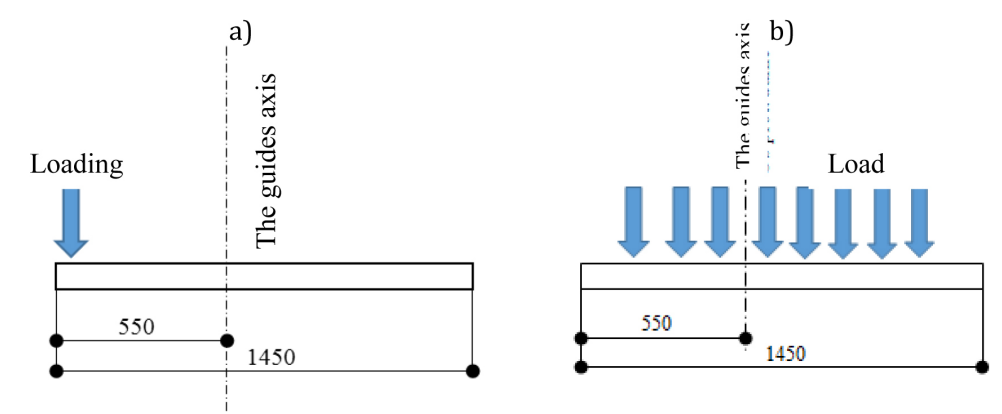

Fig. 4. The loading scheme of the lift carrying frame: a) during loading, b) when operated.

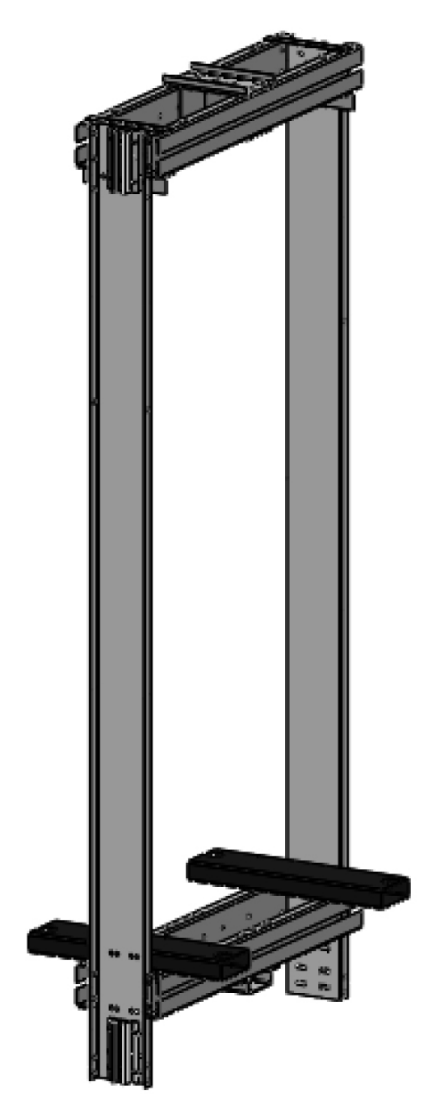

Fig. 5. Spatial model of the modernised lift carrying frame before optimisation.

It was assumed that huge displacements can appear in the optimized model caused by the loading. That is why the concept can be nonlinear from the geometrical point of view. The incremental and iteration Newton-Raphson method was used for the calculations $[1,3]$.

\section{The results of numerical calculations}

A numerical analysis was conducted for two design options of the carrying frame: before and after modifications of the structure in two versions of the load. Detailed properties of the carrying frame with FEM mesh applied are presented in Fig. 7.

The results of numerical simulation for the stresses generated in the structural element of the frame in the second version of loading are presented in Fig. 8. In order to reflect the frame working conditions, the fixed mounting of the frame on the lines was used. The sliding mounting was used on the shoe guides. The loading of a total value of $9550 \mathrm{~N}$ was applied to four positions where the lift cabin presses together with the weightcarrying on the semi-platform profiles. The numerical analysis in the scope of stresses received in simulation proved that the semi-platform profiles are the most critically stressed elements of the frame. The value of stresses generated in places where the loading is applied, approximates $70 \mathrm{Mpa}$. In the profiles located in the upper part of the frame, the generated stresses are close to the value of $55 \mathrm{MPa}$. The maximum stresses generated in the structural elements of the frame are presented in Fig. 8.

The numerical analysis results for the $1^{\text {st }}$ version of loading are presented in Fig. 10 and Fig. 11. In order to reflect the frame operating conditions, the fixed mounting of the frame on the lines and on the shoe guides was used. The loading of a total value of $2160 \mathrm{~N}$ was applied in 2 places where the lift cabin threshold is pressed during the cabin loading.

Figure 12 presents the comparison of the obtained results for the stresses of the lift carrying frame elements before the profile optimization due to the numerical analysis in two versions of loading.

Analogous numerical simulation was conducted for the carrying frame with design modifications proposed the results of which are presented in Figures 13, 14 and 15.

The values of stresses in respective assemblies of the frame in relation to the loading scheme applied are presented in Fig. 16. Both, 
a)

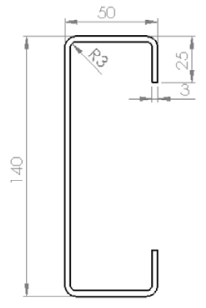

b)

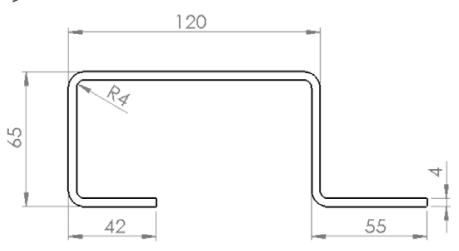

Fig. 6. Transversal dimensions of the frame carrying beam a) and semi-platform b).

a)

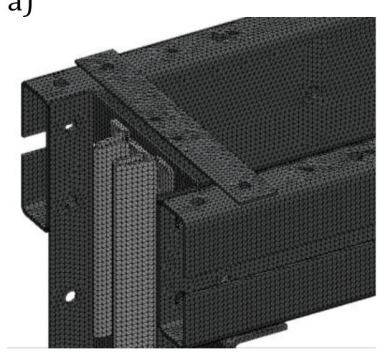

b)

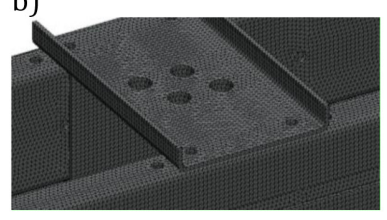

c)

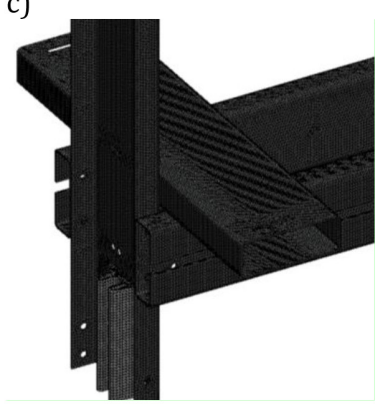

Fig. 7. Discrete model of the carrying frame before design modifications: a) the frame shoe guide, b) the carrying lines mounting, c) a semi-platfrom.

in the first and in the second case, the values of stresses are below the values that are acceptable for the assumed material.

The simulation results show that depending on the loading scheme the greatest effort is made by the upper assembly of the beams in the second scheme of loading. It is due to the fact that the frame is hung on the lines when the lift is operated. Regardless of the loading scheme, the semi-platform profiles are the second most strenuous element of the frame. However, due to the values of stresses received for the respective elements of the frame, the construction optimisation was possible in terms of the profiles modification, maintaining a safety coefficient at least at the level of 3 . a)

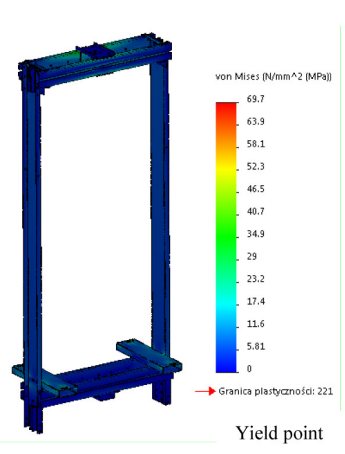

b)

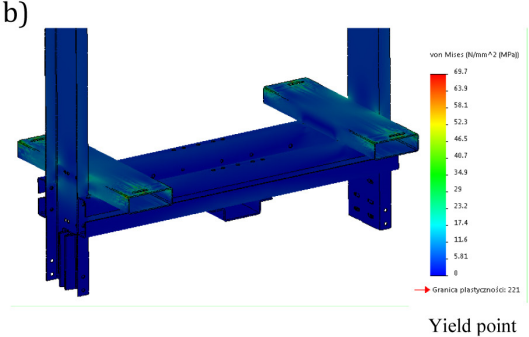

c)

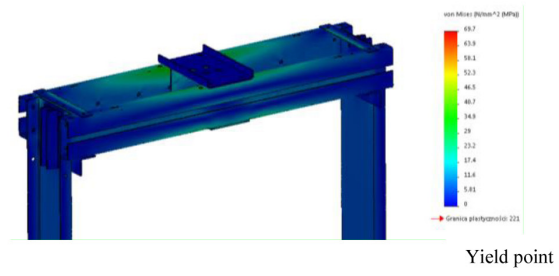

Fig. 8. The numerical analysis results for the lift carrying frame before the design optimisation: a) the frame model, b) the semi-platform profiles, c) the carrying lines mounting 
a)

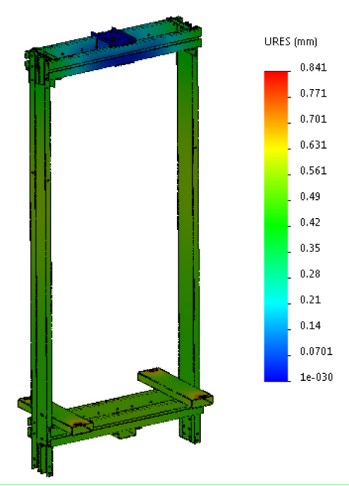

b)

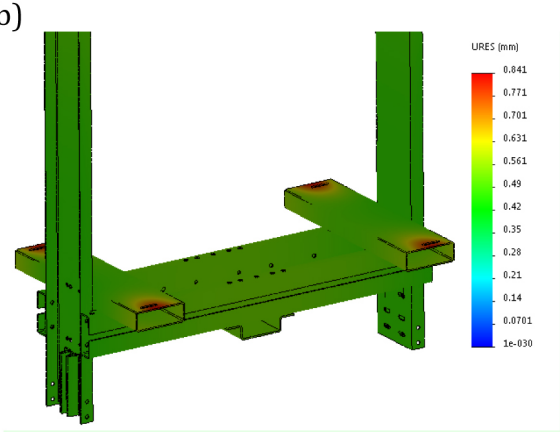

Fig. 9. The numerical analysis results for the lift carrying frame before the construction optimisation in the scope of displacements: a) the frame model, b) semi-platform profile

a)

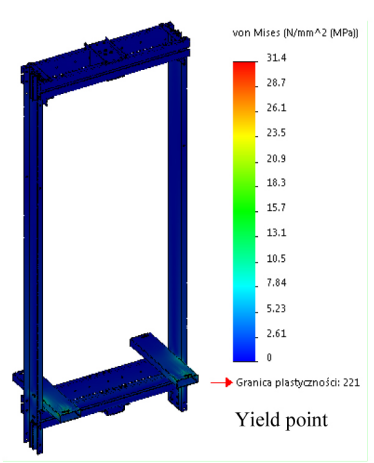

b)

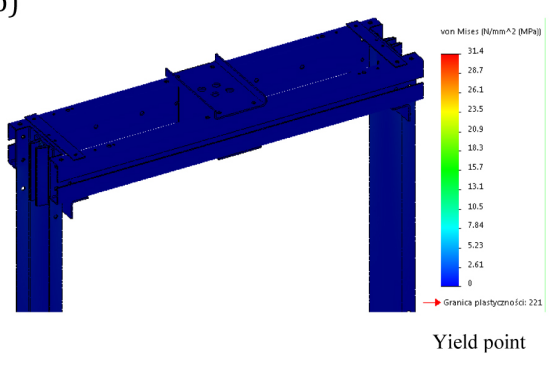

c)

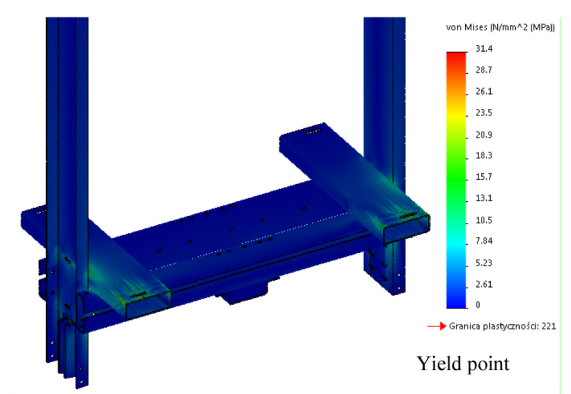

Fig. 10. The numerical analysis results for the lift carrying frame before the construction optimisation: a) the frame model, b) semi-platform profiles, c) the carrying lines mounting

a)

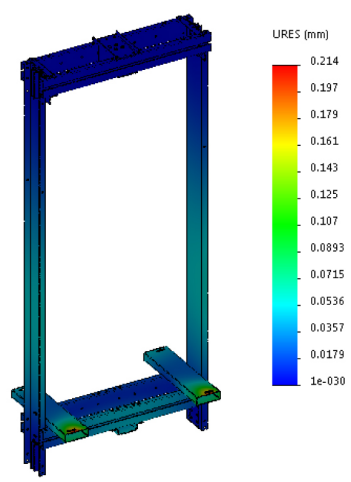

b)

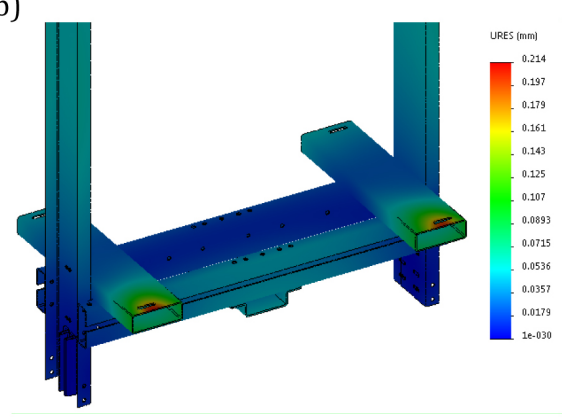

Fig. 11. The numerical analysis results for the lift carrying frame before the construction optimisation in the scope of displacements: a) the frame model, b) the semi-platform profiles 


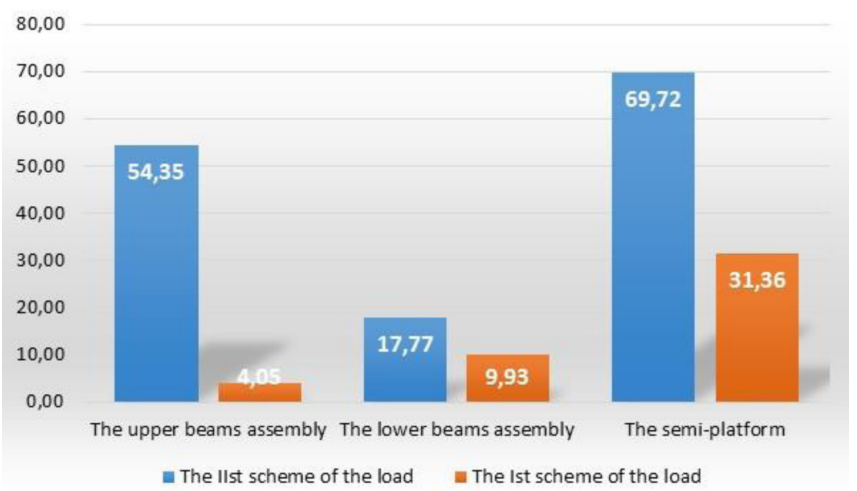

Fig. 12. The values comparison of the stresses generated in the lift carrying frame subassemblies before design modifications due to the loadings present in regular operation

a)

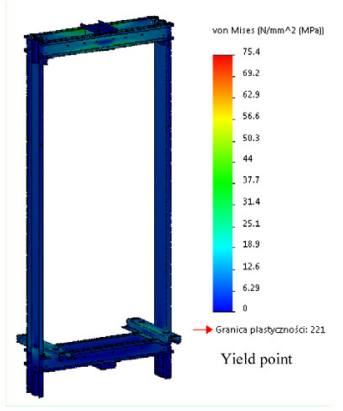

b)

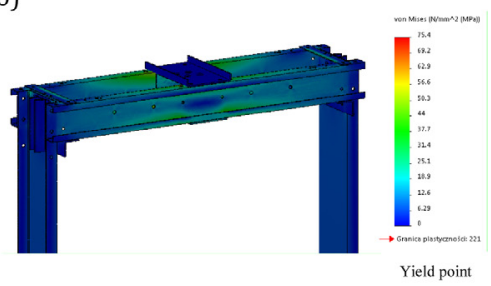

c)

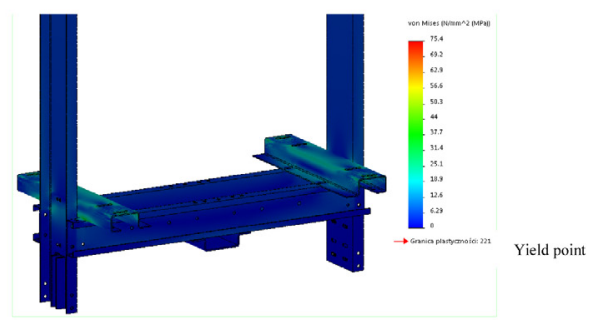

Fig. 13. The numerical analysis results for the lift carrying frame stresses after the construction optimization with the $2^{\text {nd }}$ scheme of loading: a) the frame model, b) the semi-platform profile, c) the carrying lines mounting

a)

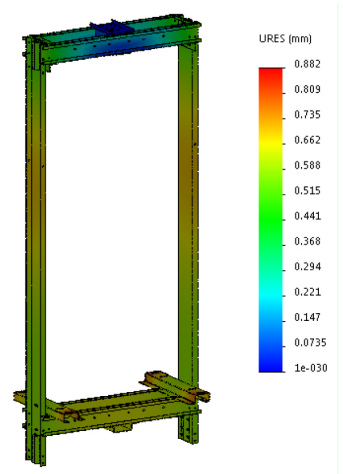

b)

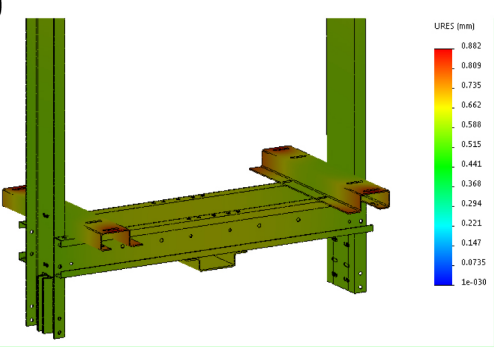

Fig. 14. The numerical analysis results for the lift carrying frame elements after the construction optimization in the scope of displacements with the $2^{\text {nd }}$ scheme of loading: a) the frame model, b) the semi-platform profile 
a)

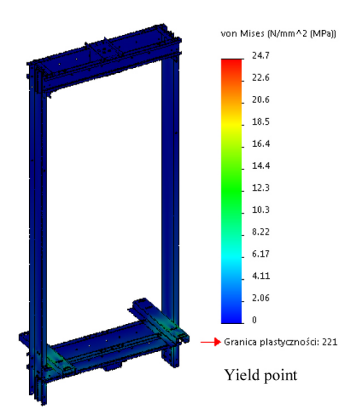

b)

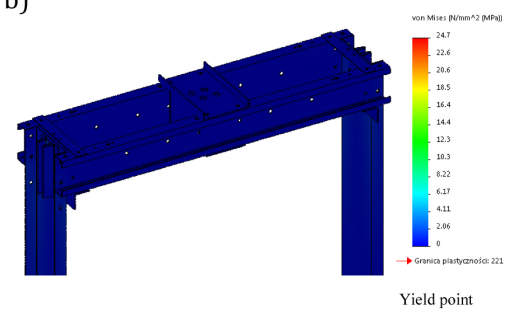

c)

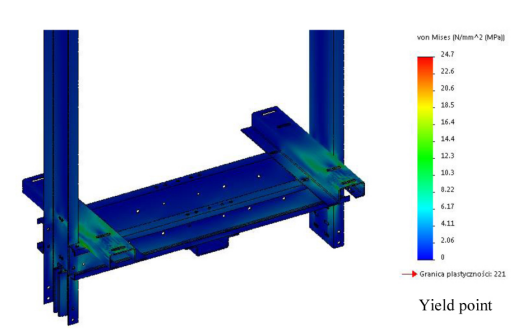

Fig. 15. The numerical analysis results for the lift carrying frame stresses after the construction optimization with the $1^{\text {st }}$ scheme of loading: a) the frame model, b) semi-platform profile, c) the carrying lines mounting

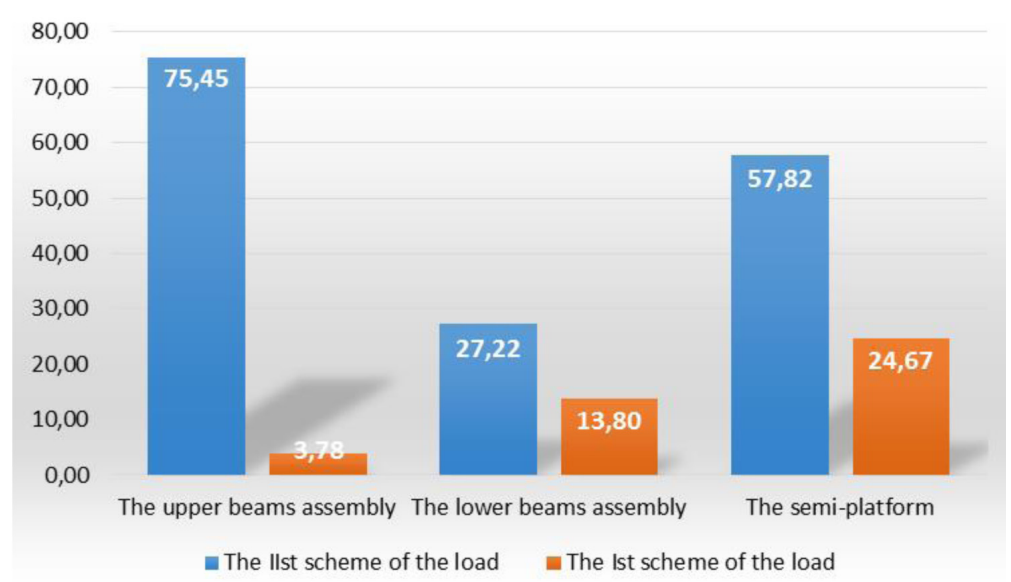

Fig. 16. The comparison of the stresses values generated in the lift carrying frame subassemblies after design modifications due to the loadings present in regular operation

\section{CONCLUSIONS}

1. The method of modelling the carrying systems presented in this research paper by using Finite Element Method allows conducting the analysis of deformation degree and the level of carrying elements effort under complex external loadings applied. The possibility to carry out the analysis at the stage of virtual prototyping is important when new design solutions are sought and when there are too many unknown design parameters while designing some complicated elements of machines and mechanisms. The knowledge on the stresses distribution in the elements belonging to the carrying system is a significant issue which allows evaluating the adopted concept. A numerical analysis allows optimising the model parameters in order to design the most favourable solution to transmit specific operation loadings. The conducted analysis was used to evaluate the necessary modifications of design details to receive optimum solution.

2. The numerical calculations conducted with Finite Element Method for the friction lift carrying frame proved that it is possible to reduce the frame mass at the expense of its resistance.

3 . The carrying frame modification enabled to reduce its mass by $20 \%$ and to maintain the construction stiffness and functionality. The 
presented modification is significant from the operational and economical point of view.

4. The prepared solid model of the friction lift carrying frame reflects the operating conditions of the structure under a fixed loading very well. The conducted analysis allowed evaluating the proposed design solution. It constitutes the basis for implementing necessary manufacturing changes.

5. The proposed modifications for the frame channel bars profiles and the semi-platform profiles were introduced to production. They reduced the manufacturing costs and eventually the final costs.

\section{Acknowledgements}

The research study was financed within cooperation with LIFT POL company in the scope of the company development in the passenger lifts modernization market in Poland.

\section{REFERENCES}

1. Czmochowski J., Smolnicki T., Rusiński E.: Advanced Finite Element Method in the supporting structures. Of. Wydawnicza Politechniki Wrocławskiej, Wrocław 2000.

2. Dębski H., Koszałka G., Ferdynus M.: Application of FEM in the analysis of the structure of a trailer supporting frame with variable operation parameters. Eksploatacja i Niezawodność - Maintenance and reliability 2012; 14 (2): 107-114.
3. Kacprzyk Z., Rakowski G.: Finite Element Method in the structures mechanics. Of. Wydawnicza Politechniki Warszawskiej, Warszawa 2005.

4. Lonkwic P., Różyło P., Dębski H.: Numerical and experimental analysis of the progressive gear body with the use of finite-element method. Eksploatacja i Niezawodność-Maintenance and Reliability 2015; 17 (4): 544-550, http://dx.doi.org/10.17531/ ein.2015.4.9.

5. Markowski T., Mucha J., Witkowski W.: FEM analysis of clinching joint machine's c-frame rigidity. Eksploatacja i Niezawodność - Maintenance and reliability 2013; 15 (1): 51-57.

6. Meeker D.: Finite Element Method Magnetics. USA 2015

7. Nguyen-Xuan N., Rabczuk T., Stéphane B., Debongnie F. A smoothed finite element method for plate analysis. Computer Methods in Applied Mechanics and Engineering 2008; 197 (13-16), https://doi.org/10.1016/j.cma.2007.10.008

8. Ping Zhua Z., Leiabc X., Liewab K., M.: Static and free vibration analyses of carbon nanotubereinforced composite plates using finite element method with first order shear deformation plate theory. Composite Structures 2012; 94 (4), https://doi.org/10.1016/j.compstruct.2011.11.010

9. PN EN 81-20 Standard, Safety rules for the construction and installation of lifts. Part 20: Passenger and goods-passenger lifts, Warszawa 2017

10. RaoS. Singiresu:TheFiniteElementMethodinEngineering. Butterworth-Heiner of Elsevier, USA 2018

11. Szydło K., Longwic R.: Diagnostics of the passenger lift gear. Advances in Science and Technology Research Journal 2018; 12(1): 26-35. 